\title{
Correlation between Ink Thickness and "Shrink Sleeve" Flexographic Print Quality at a Stable Friction Coefficient
}

\author{
Igor Zjakić*, Ivana Ljevak, Albulena Bilalli
}

\begin{abstract}
Flexographic technology usage is increasing in recent years. Predicted growth in the technology usage intensifies the demand for improved quality. It is expected that flexographic printing will achieve greater results than ever before. Since this technique is used in the printing of shrink sleeve packaging, it is imperative to meet the technical and economic requirements of the shrink sleeve product. This is primarily to ensure gliding of the white printing material. The amount of white should be as small as possible, making the sliding of the material optimal and the quality of the print better. Therefore, the quality of the printing was measured by changing the conditions of slippage and white color. This research has established a correlation between the thickness of the white layer and the reduction of print quality over thin lines.
\end{abstract}

Keywords: flexographic printing; gliding; ink layer; print quality; shrink sleeve

\section{INTRODUCTION}

Flexographic printing is a fast-paced printing process that has extensive application in the packaging industry. The packaging industry produces high quality graphics on coated, unopened paper and board, and on flexible foils. Flexographic printing is a printing technique that uses flexible sheets with elevated printing elements with a direct printing principle on the substrate [1]. Flexographic printing is a highly sensitive printing technique, and the printing form is easily adapted to all print media. Precisely because of its suppleness and softness, the plate under pressure combined with low viscosity color can produce an extremely large increase in rastertone value [2]. Thanks to the elastic printing elements, this printing technique can be applied on a variety of intricate and inadequate printing presses, such as: thin films, flexible and rigid films, almost all papers, cartons of different thicknesses and grammars, packing materials of rough surfaces and similar.

A variety of parameters are influenced by the print quality. Some of the most important parameters are the shapes of the dot element, the size of the dot cell, and the pressure on the surface to which it is printed. These two characteristics define the growth of rastertone value which is essential for the study of the thickness of the line in this research $[3,4]$.

In flexographic printing "shrink sleeve" technology, it is necessary to apply white color that, besides visual application has a role in defining sliding material, so the amount of white color used for this need is extremely important in the overall product price [5]. Accordingly, the most important commercial part of the workflow is a flexographic process of color management that obtains predictable and repeatable prints, whether it is a color press, or to print a background white color [6]. In many cases, the price of the ink is about $4-6 \%$, and the printing media $60-70 \%$ of the total production costs. Poor color management, especially printed white color on transparent materials, which most often makes the surface of the entire printing press, can lead to increased production costs [7]. Shrink sleeve labels are made from many types of macromolecular materials, PVC, PET, PET-G, OPS, PLA (polylactic acid) and other hybrid materials for specific applications [8].

\subsection{Flexographic Technology}

The research in this paper was done by printing control strips (predefined printing fields) with a borderline of high quality reproduction at different thicknesses of white layers. Flexographic technology is specific in color dosage control. It is defined by anilox line count and volume.

Proper selection of anilox rollers allows for achieving a target of Solid Ink Density (SID) and permissible deviations of color difference $\Delta E$, in order to obtain a consistent and repeatable print quality [5].

Further, it is necessary to determine which volume of anilox rollers ( $B C M$ - billion cubic microns) meets the highest color density limit. The highest color density limit is acceptable because it leaves room for wear and less filling of the anilox roller. For example, if the $1.8 B C M$ anilox roller gives a color density of 0.95 , it can be predicted that the new $2.0 B C M$ anilox roller, which gives a color density of 1.05 , after a certain time of application (when it will transmit 1.8 $B C M$ ) and still deliver results within the tolerance limit.

\section{2 Printing Parameters}

The volume of anilox rollers is calculated in billion cubic microns per inch square $\left(10^{9}\right)$, so the unit of measurement for the volume of the anilox roller can be calculated by the expression [18]:

$$
\frac{B C M}{\text { inch }^{2}}=\frac{10^{9} \times 10^{-12}}{6.4516 \times 10^{-4}}
$$

Above expression can be transfered to $\mathrm{cm}^{3} / \mathrm{m}^{2}$ and after calculation we get:

$$
\frac{B C M}{\text { inch }^{2}}=1.55 \frac{\mathrm{cm}^{2}}{\mathrm{~m}^{2}},
$$


following

$$
\frac{\mathrm{cm}^{2}}{\mathrm{~m}^{2}}=\frac{1}{1.55}=0.6455 \frac{B C M}{\mathrm{inch}^{2}} \text {. }
$$

The volume parameter defines theoretical amount of ink held in anilox cells in a square inch or square centimeter. So the ink layer thickness calculation is obtained by:

$$
\text { Ink thickens }=\frac{B C M}{0.65} .
$$

Since the ink of the cells in the printed plate is transferred by about $50 \%$ due to the "contact" of the printing form and the anilox roller, and $50 \%$ due to the contact of the printing press and the printing substrate, the actual amount of ink on the printed media can be calculated as shown in Tab. 1.

Table 1 Ink layer thickness on the substrate in regards to volume of anilox roller

\begin{tabular}{|c|c|c|c|}
\hline \multicolumn{2}{|c|}{ Volume of anilox roller } & $\begin{array}{c}\text { Ink layer thickness at } \\
\text { printing form }\end{array}$ & $\begin{array}{c}\text { Ink layer thickness on } \\
\text { the substrate, } \mu \mathrm{m}\end{array}$ \\
\hline$B C M$ & $\mathrm{~cm}^{3} / \mathrm{m}^{2}$ & 0.77 & 0.39 \\
\hline 1 & 1.55 & 1.55 & 0.77 \\
\hline 2 & 3.10 & 2.32 & 1.16 \\
\hline 3 & 4.65 & 3.10 & 1.55 \\
\hline 4 & 6.20 & 3.87 & 1.94 \\
\hline 5 & 7.75 & 4.65 & 2.32 \\
\hline 6 & 9.30 & 5.42 & 2.71 \\
\hline 7 & 10.84 & 6.20 & 3.10 \\
\hline 8 & 12.39 & 6.97 & 3.49 \\
\hline 9 & 13.94 & 7.75 & 3.87 \\
\hline 10 & 15.49 & & \\
\hline
\end{tabular}

By producing pressforms for flexo printing with $\mathrm{CtP}$ technology it is necessary to satisfy the requirements where we have at least 256 different shades for each color which shall be printed. As the 8 bit color data provides the ability to print 16.7 million colors, it is necessary to determine the size of the dot cell and the number of gray shades that can be printed with the CtP device.

Cell size and number of gray levels are calculated according to:

Cell size $=\frac{p p i}{l p i}$

Number of gray levels $=\left(\frac{p p i}{l p i}\right)^{2}+1$,

where: $p p i$ - output resolution of a CtP device defined by the number of pixels per inch; lpi - the line screen is defined by the number of lines per inch.

Since demands in graphic reproduction on quality of printing are usually very high, it is important to make high quality printing plate as well. This can be done by conventional polymers and standard digital CtP polymerization processes on the polymer plate, then by UV oscillation of two-InkJetCtP technology that prints the mask on the top of the board and the LED with UV technology with the main exposure inside the CtP [10].
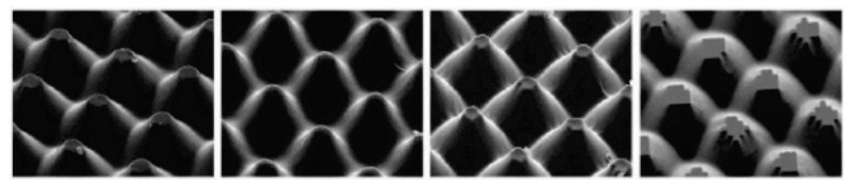

Figure 1 Influence of different lighting technologies on the geometry of the dot element [11]

The aim of each reproduction is to optimize the production chain so that the information about color remains as true to the original as possible during the transition from the original to print [12]. During the transformation of such information, from phase to phase, there is possibility of losing tones and irregular transformation is possible.

The transfer of tonal values and the reproduction quality depends on the adherence of the ink to the printing plate and the printing substrate. Theoretically defined, the screen element loses its theoretical value by imaging the printing plate and, in this way, increased or decreased adherence of the ink comes into play and consequently has an effect on quality of printing. Apart from the ink transfer onto the printing plate, the ink quantity that is transferred to the printing substrate depends on the transfer time, the strength of the pressure on the printing substrate, the rheological properties of the ink, the temperature of the ink and the properties of the printing substrate, and can be expressed by Eq. (7) [13].

$p=\left(1-\mathrm{e}^{-(a m) x}\right)\left\{w_{0}\left(1-\mathrm{e}^{\left(-\frac{m}{w_{0}}\right)}\right)+\alpha\left[m-w_{0}\left(1-\mathrm{e}^{\left(-\frac{m}{w_{0}}\right)}\right)\right]\right\}$

where: $p$ - quantity of the ink transferred onto the printing substrate $\left(\mathrm{g} / \mathrm{m}^{2}\right) ; m$ - quantity of ink on the printing substrate $\left(\mathrm{g} / \mathrm{m}^{2}\right) ; a$ - smoothness of the printing substrate $\left(\mathrm{m}^{2} / \mathrm{g}\right) ; w_{0}$ maximal adsorption of ink $\left(\mathrm{g} / \mathrm{m}^{2}\right) ; \alpha$ - ink separation factor; $x$ - machine factor.

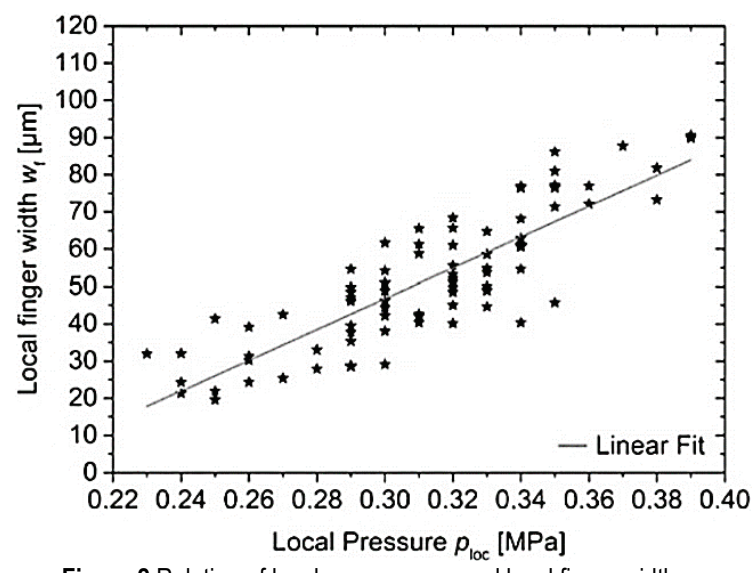

Figure 2 Relation of local pressure $p_{\text {loc }}$ and local finger width $w_{\mathrm{f}}$

Earlier research by A. Lorenz et al. [14] show that the dependence of the pressure and the surface size by adapting the data to the linear function as shown in Fig. 2. 


\section{METHODS}

In this research, the polyvinyl foil (PVC) is used in the printing of shrink sleeve packaging. The prints were made by printing thin lines on the white ink layer to determine the dependency in the conditions of satisfactory print quality as showed on Fig. 3.

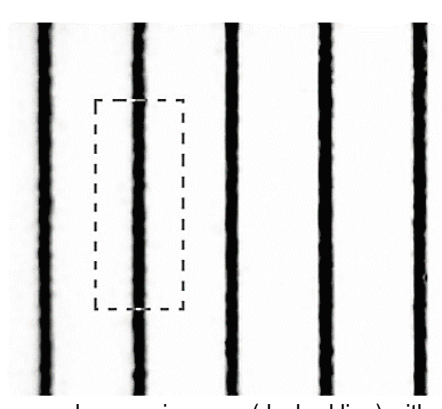

Figure 3 Printed lines and measuring area (dashed line) with magnification (200x)

The printing machine on which the foils were printed was: Nilpeter FA 4. The test line was $10 \mu \mathrm{m}$ thin. The foil that was used for printing was transparent foil with thickness of $40.50 \mu \mathrm{m}$, manufacturer Bilcare. The lines were printed on 6 different volumes of ink layer, respectively on the thicknesses of the white layer as shown in the Tab. 2.

Table 2 Layer thickness on the substrate relative to the volume of anilox roller used for research

\begin{tabular}{|c|c|c|c|c|}
\hline \multirow{2}{*}{$\begin{array}{c}\text { Sample } \\
\text { No. }\end{array}$} & \multicolumn{2}{|c|}{ Volume of anilox roller } & Ink layer thickness on & Opacity $\%$ \\
\cline { 2 - 3 } & $B C M$ & $\mathrm{~cm}^{3} / \mathrm{m}^{2}$ & 1.16 & 53 \\
\hline 1 & 3 & 4.65 & 1.94 & 53 \\
\hline 2 & 5 & 7.75 & 2.32 & 55 \\
\hline 3 & 6 & 9.30 & 2.71 & 56 \\
\hline 4 & 7 & 10.84 & 3.10 & 56 \\
\hline 5 & 8 & 12.39 & 3.49 & 57 \\
\hline 6 & 9 & 13.94 & & \\
\hline
\end{tabular}

After printing the foil, a sliding material test was performed to determine whether gliding meets the needs of shrink sleeve technology. Material sliding test is performed on the SST3-XS, RDM.

In the last part of the experiment, the thickness of the printed lines was measured and the image was greatly enlarged by the ImageJ software, at which edge of the line was lost. After measuring the thickness of the line, the function of addiction was calculated. The measurements of measured thickness dependence of the layer thickness on the color layer thickness were chosen using two functions: linear functions and logarithmic functions with a natural number basis e. The relative coefficients of these functions are determined by the least mean squares method [15].

\section{RESULTS AND DISCUSSION}

After the film was printed, the sliding material testing of the material was applied to the sliding test and the following results were obtained where we can see coefficient of friction for each sample (Fig. 4).

The slippage results are compared to the actual sliding test on the machine to see if some result from satisfactory foam behavior when stretching the material. After the testing phase, it was determined that all the results met the quality condition of the actual production, meaning that all samples can be used on the slider factor.

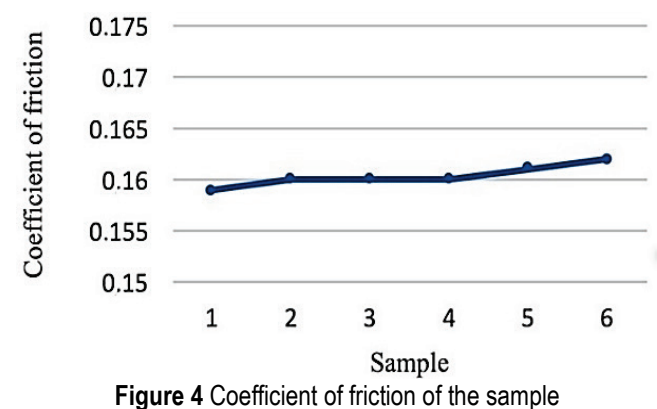

Prints on different thicknesses of white layers were recorded with camera enlargement and were analyzed with the usage of ImageJ software. As the image analysis based on the establishment of different brightness on the margins of the analyzed thin lines [16], the results are shown as the brightness level on the gray level in the intro of 0-255. Since ImageJ works on the principle of reflected light, the different values of light gray for this study are not relevant given the degree of tolerance of the camera itself and the measurements.

The data on the prints is viewed at a moment when there is a significant shift of gray level since this shift implies an edge between the printed and unsealed part of the line.

The results are shown in the following figures.

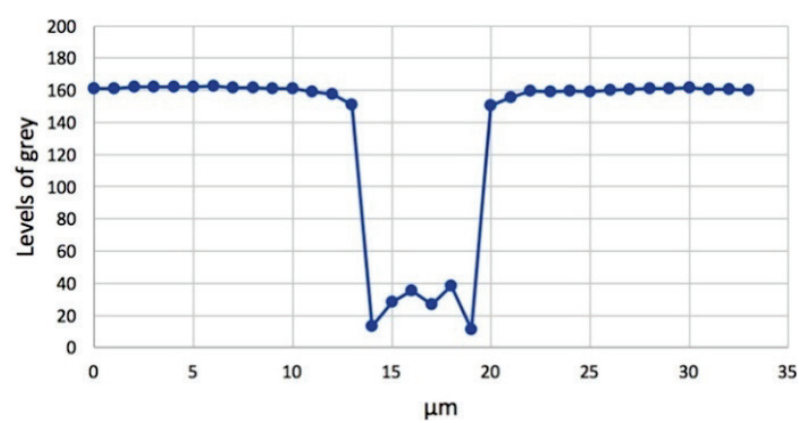

Figure 5 Levels of gray for prints with $3 \mathrm{BCM}$ and ink amount of $1.16 \mathrm{~cm} 3 / \mathrm{m}^{2}$

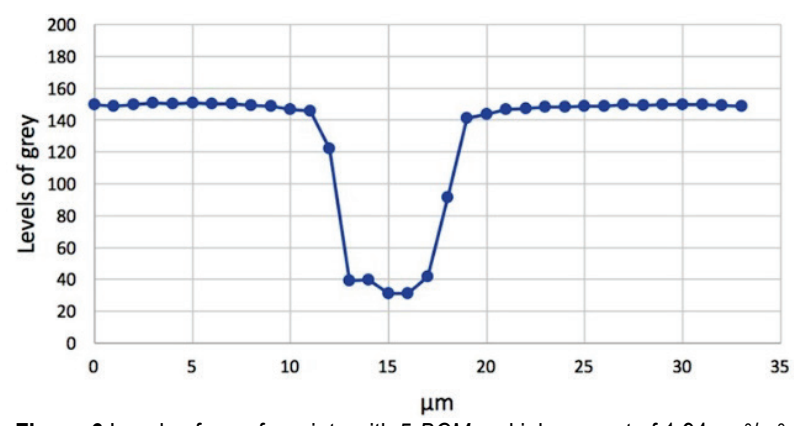

Figure 6 Levels of gray for prints with 5 BCM and ink amount of $1.94 \mathrm{~cm}^{3} / \mathrm{m}^{2}$

By analyzing these graphs, the points of sudden change in brightness were determined, respecting, the said method determines the actual width of the line on the prints having different thicknesses of the white layer. 


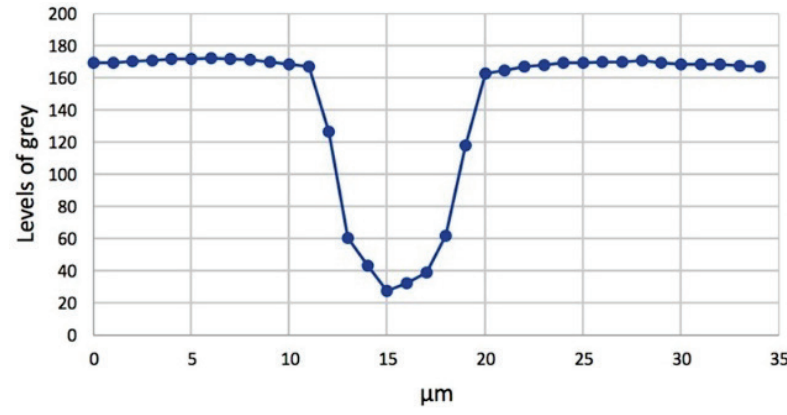

Figure 7 Levels of gray for prints with $6 \mathrm{BCM}$ and ink amount of $2.32 \mathrm{~cm} 3 / \mathrm{m}^{2}$

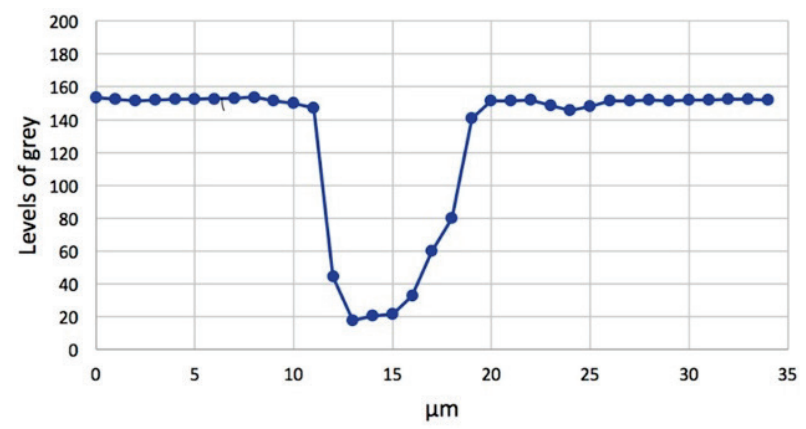

Figure 8 Levels of gray for prints with $7 \mathrm{BCM}$ and ink amount of $2.71 \mathrm{~cm}^{3} / \mathrm{m}^{2}$

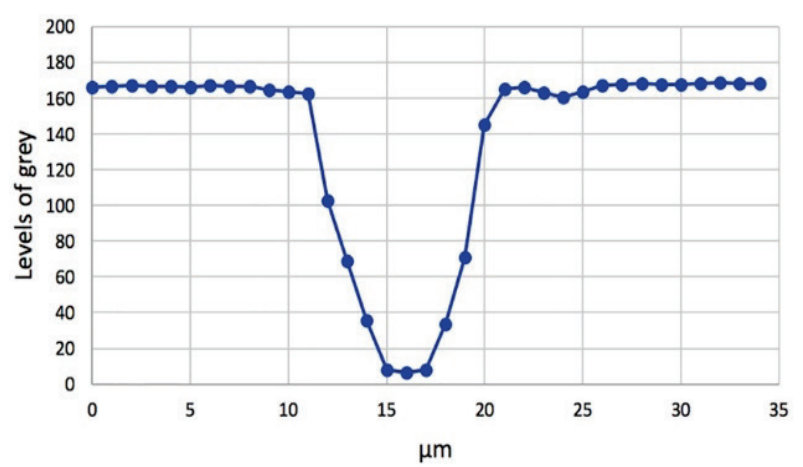

Figure 9 Levels of gray for prints with $8 \mathrm{BCM}$ and ink amount of $3.10 \mathrm{~cm}^{3} / \mathrm{m}^{2}$

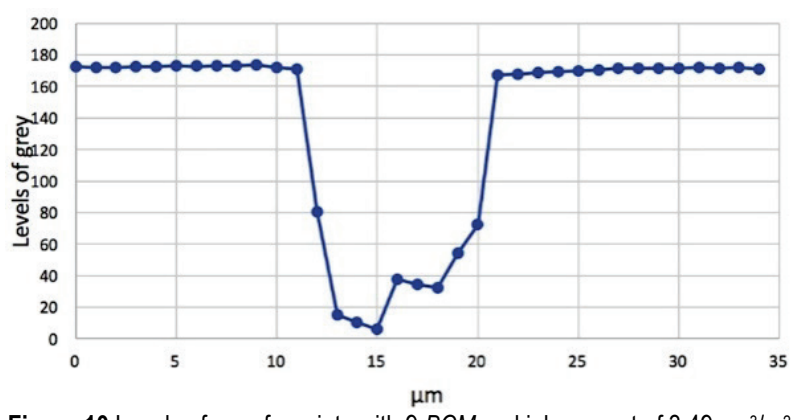

Figure 10 Levels of gray for prints with $9 \mathrm{BCM}$ and ink amount of $3.49 \mathrm{~cm}^{3} / \mathrm{m}^{2}$

This difference is expected, since in thicker layers the ink of the second color (in this case the thin line) penetrates more in ink and the color discoloration and geometric and optical growth of rastertone values occur [17].

For this research, the increase in rastertone values is not calculated, just the function required to show how the size of the printed thin lines changes in the manner of increasing the ink layer.
Table 3 Measured line widths

\begin{tabular}{|c|c|c|}
\hline Sample & Thickness, $\mu \mathrm{m}$ & Line width, $\mu \mathrm{m}$ \\
\hline 1 & 1.16 & 6.9 \\
\hline 2 & 1.94 & 8.1 \\
\hline 3 & 2.32 & 8.8 \\
\hline 4 & 2.71 & 9.5 \\
\hline 5 & 3.10 & 9.7 \\
\hline 6 & 3.49 & 10 \\
\hline
\end{tabular}

The least mean squares method calculates the parameters for the logarithmic function.

Table 4 Results obtained by the least mean squares method

\begin{tabular}{|l|c|c|c|c|}
\hline & \multicolumn{2}{|c|}{ Linear function } & \multicolumn{2}{c|}{ Logarithmic function } \\
\hline Coeff. & 0.600 & 6,733 & 1.760 & 6,903 \\
\hline Std. Err. & 0.087 & 0,340 & 0.059 & 0,074 \\
\hline R2, sey & 0.922 & 0,365 & 0.995 & 0,088 \\
\hline F, df & 47,250 & 4,000 & 877,214 & 4,000 \\
\hline ssreg, ssresid & 6.300 & 0,533 & 6.802 & 0,031 \\
\hline
\end{tabular}

With the least mean squares method we can see the relation between logarithmic and linear functions and the thickness of the ink layer on the print.

These generated functions are represented by Fig. 11.

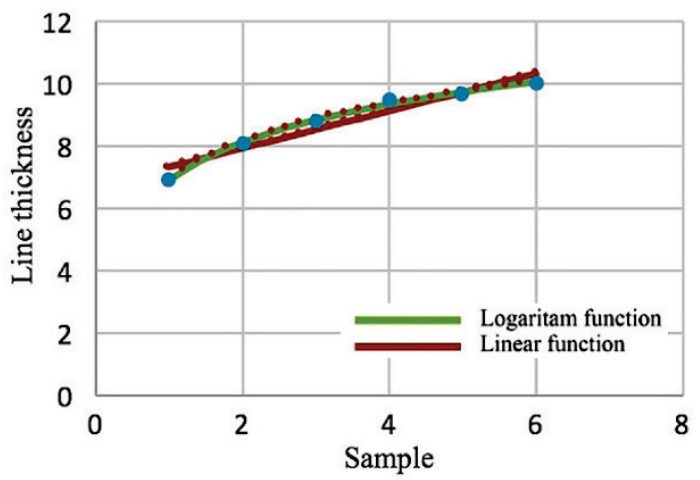

Figure 11 Linear and logarithmic function of the line thickness and the thickness of the ink layer on the print

\section{CONCLUSIONS}

This research confirms that the thickness of the white color film is directly influenced by the quality of the prints. It has been established that by increasing the thickness of the white layer, the increase in the width of thin strips is performed, and affects dot elements that can lead to decrease in print quality. As the width of the line was increased when printing, the increase in the printing element resulted in a dot gain.

The amount of white printing in flexographic printing should be as small as possible for commercial reasons. However, as the amount of white color affects the material sliding coefficient and the transparency of the material when the foil is printed for non-white products, then the thickness of the white coat affects the gliding factor but also reduces the opacity that affects the experience of non-white packaging as showen on Fig. 4.

This research has established a correlation between the thickness of the white layer and the reduction of print quality over thin lines (Fig. 11). By calculating the dependence 
obtained by the least squares method, the dependence of decreasing the print quality by increasing the line thickness can be better illustrated by the logarithmic function since the deviations in relation to the linear function are considerably smaller.

\section{REFERENCES}

[1] Kipphan, H. (2001). Handbook of Print Media, Springer, Berlin, Chapter 2-a.

[2] Miljković, P., Valdec, D., Matijević, M.,The Impact of Printing Substrate on Dot Deformation in Flexography. Tehnički vjesnik, 25 (Supplement 2), 509-515. https://doi.org/10.17559/TV-20170710152140

[3] Valdec, D., Zjakić, I., \& Milković, M. (2013). The influence of variable parameters of flexographic printing on dot geometry of pre-printed printing substrate. Tehnički vjesnik, 20(4), 659667. Retrieved from https://hrcak.srce.hr/106698.

[4] Zjakić, I., Bates, I., \& Milković, M. (2011). A study of dot gain and gamut for prints made with highly pigmented inks. Tehnički vjesnik, 18(2), 227-235. Retrieved from https://hrcak.srce.hr/69588.

[5] Foundation of Technical Association. (2013). FLEXOGRAPHY: Principles and Practices $6.0 .6^{\text {th }}$ ed., New York.

[6] Wypych, G. (Ed.) (2019). Handbook of Solvents (Third Edition), Volume 2: Use, Health, and Environment, 901-1124.

[7] Izdebska, J. (2016). Flexographic printing. Printing on Polymers (Fundamentals and Applications), ScienceDirect, 179-197. https://doi.org/10.1016/B978-0-323-37468-2.00011-7

[8] Krystosiak, K. (2017). Prediction Method for Winding Parameters in Label Converting Process with Data Mining Tools. The $7^{\text {th }}$ International Conference on Engineering, Project, and Production Management, Procedia Engineering, 182, 373-380. https://doi.org/10.1016/j.proeng.2017.03.116

[9] Gooran, S. (2005). Hybrid halftoning, a useful method for flexography. Journal of Imaging Science and Technology, 49(1), 85-95.

[10] Bould, D. C., Claypole, T. C., Bohan, M. F. J., \& Gethin, D. T. (2004). Deformation of Flexographic Printing Plates. The $56^{\text {th }}$ TAGA Technical Conference, 146-162.

[11] Stebani, U. (2012). New UV expose technology for photopolymer plates. Flexo \& Gravure Global, 18(3), 14-15.

[12] Lorenz, A., Kalio, A., Hofmeister, G. T., Nold, S., Kraft, A., Bartsch, J., Wolf, D., Dreher, M., Clement, F., \& Biro, D. (2013). Flexographic Printing - High Throughput Technology for Fine Line Seed Layer Printing on Silicon Solar Cells. Proceedings of the $28^{\text {th }}$ EUPVSEC, 1017-1023. https://doi.org/10.4229/28thEUPVSEC2013-2EO.2.6

[13] Gustavson, S. (1997). Dot Gain in Colour Halftones. PhD Thesis, (Linköping University, Linköping, 25-36.

[14] Lorenz, A., Gredy, C., Senne, A., Beyer, S., Yao, Y., Papet, P., Ufheil, J., Reinecke, H., \& Clement, F. (2016). Flexo-printed busbarless solar cells for multi-wire interconnection. Energy Procedia, 98, 46-60. https://doi.org/10.1016/j.egypro.2016.10.080

[15] See https://web.math.pmf.unizg.hr/ bruckler/pdf/mnk.pdf

[16] Claypole, T. C., Bould, D., Hall, R., Jewell, E., \& Gethin, D. (2008). Flexo printing of fine lines. TAGA Proceedings, 252266.

[17] Johnson, J. (2008). Aspects of Flexographic Print Quality and Relationship to some Printing Parameters. PhD Thesis, Karlstad University, Germany.

[18] Valdec, D. (2013). Utjecaj promjenjivih parametara fleksotiska na geometriju rasterskog elementa predotisnute tiskovne podloge. PhD Thesis, Grafički fakultet, Zagreb, Croatia (in Croatian).

\section{Contact information:}

Igor Zjakic, PhD, Associate Professor

(Corresponding author)

Faculty of Graphic Art,

University of Zagreb,

Getaldićeva 2, 10000 Zagreb, Croatia

E-mail: igor.zjakic@grf.unizg.hr

Ivana Ljevak, MSc

Meteor Grupa-Labud d.o.o.

Radnička cesta 173r, 10000 Zagreb, Croatia

E-mail: ivana.ljevak@gmail.com

Albulena Bilalli, MSc

Institution Technical High School,

SH.M.T "28 Nëntori" Prishtinë,

Kalabria 12 Qershori, 10000 Pristina, Kosovo

E-mail: albulenabilalli2@gmail.com 